\title{
Staphylococcus aureus colonization in Qazvin university hospitals healthcare workers
}

\author{
S. Nazemsadati ${ }^{1}, \underline{\text { A. Allami }}^{1}$, F. Haj Manoochehri ${ }^{2}$
}

\author{
${ }^{1}$ Department of Infectious Disease, Qazvin University of Medical Sciences, Qazvin, Iran \\ ${ }^{2}$ Department of Pathology, Faculty of Medicine, Qazvin University of Medical Sciences, Qazvin, Iran \\ Corresponding Address: Abbas Allami, Department of Infectious Diseases, Bu-Ali Sina Hospital, Qazvin, Iran \\ Tel: +98-28-33333031; Email: allami9@yahoo.com \\ Received: 27 Aug 2017; Accepted: 13 Jan 2018
}

\section{Abstract}

Background: Staphylococcus aureus (SA) colonization of hospital personnel is a source of hospital acquired infections.

Objective: The aim of this study was to determine the prevalence of nasal carriage rate of SA and methicillin resistant Staphylococcus aureus (MRSA) among Health Care Workers (HCWs) at Qazvin university hospitals.

Methods: A cross sectional study was conducted among 396 employees of five teaching hospitals from October 2016 to April 2017. After obtaining informed consent and completion of the questionnaire, a sample was taken from the anterior nasal cavity for microbiology. The isolation of SA and their antimicrobial sensitivity were carried out by standard bacteriological procedures (disk diffusion and E-Test method). MRSA were confirmed by cefoxitin disk diffusion test. Chi square and independent $\mathrm{t}$ test were used to analyze the collected data.

Findings: From the $198 \mathrm{HCWs}, 32$ people (16.1\%) carried SA that the most carriers were workers of intensive care units (20.3\%). 3\% of all HCWs were identified as MRSA carriers. Colonization with SA is significantly lower among nursing and higher education. All SA isolates were sensitive to vancomycin and rifampin.

Conclusion: The rate of nasal SA (especially MRSA) carriage among HCWs of Qazvin university hospitals is low. Also, staff teaching appears to be a promising approach for reducing nasal carrier. Rifampin and mupirocin, for eradication of Staphylococcus colonization in health workers (even MRSA) are acceptable.

Keywords: Methicillin resistant staphylococcus aureus, Healthcare workers, Nasal carriage, Antimicrobial sensitivity

Citation: Nazemsadati S, Allami A, Haj Manoochehri F. Staphylococcus aureus colonization in Qazvin university hospitals healthcare workers. J Qazvin Univ Med Sci 2018; 22(2): 8-19. 


\section{كلونيزاسيون استافيلوكوكوس اورئوس در كاركنان درمانى بيمارستانهاى دانشكاه علوم يزشكى قزوين}

دكتر سيده سارا ناظم ساداتى '، دكتر عباس علامى'، دكتر فاطمه حاج منوجهرى

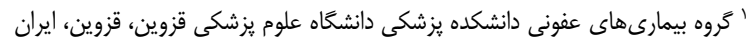

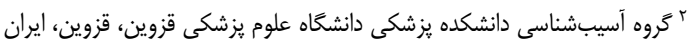

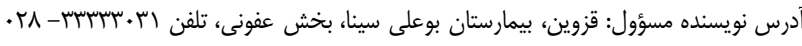

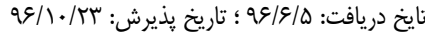

زمينه: استافيلوكوى كلونيزه شده در حفره قدامى بينى كاركنان درمانى يكى از منابع عفونت استافيلوكوكى در بيمارستان است.

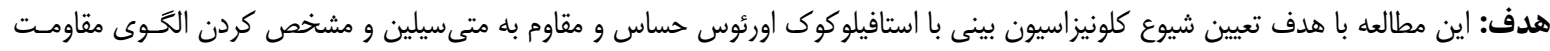

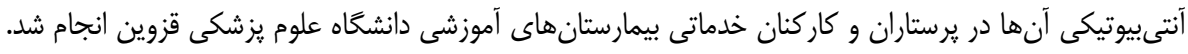

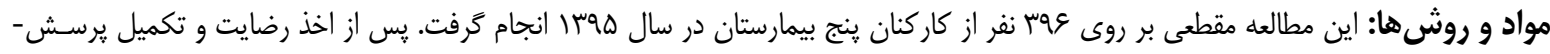

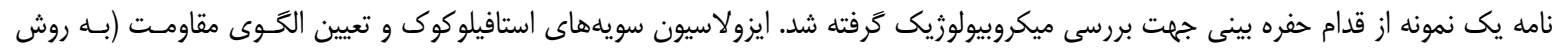

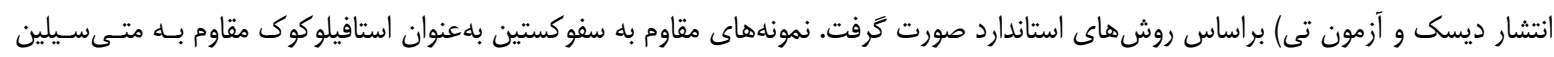
(MRSA)

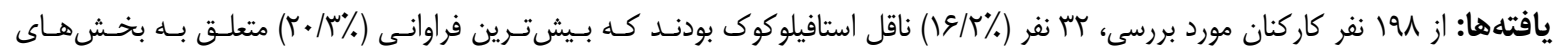

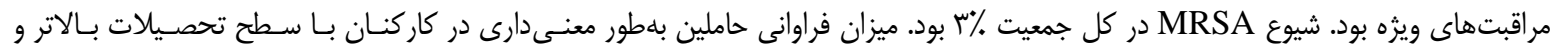

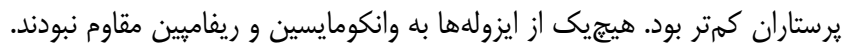

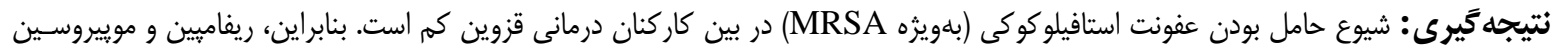

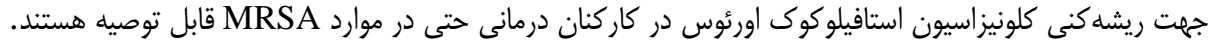

كليدوازهها: استافيلوكوك مقاوم به متىسيلين، كار كنان درمانى، حامل بينى، الكَوى حساسيت آنتىبيوتيكى

(2) مقدمه:

آن هاست.(זوّ) افراد كلونيزه بـدون علامست منبعسى بـراى

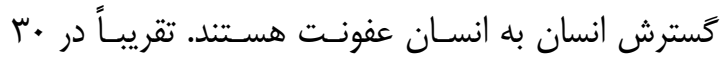
درصد افراد، استافيلوكوكوس اورئوس در مجـارى بينـى و نقاط ديخر بدن مانند زير بغل كلونيزه است؛ بـا ايـنحسال

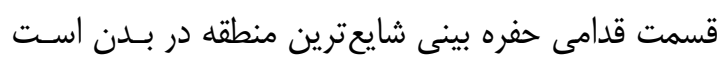

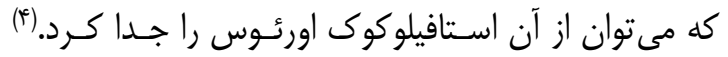
كلونيزاسيون استافيلوكوى در حفره قدامى بينسى كاركنـان درمانى بهعنوان يكى از منـابع عفونـت اسـتافيلوكوكى در

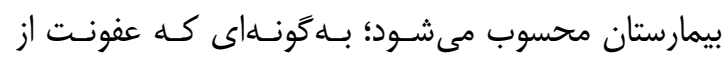
طريق تماس دست با اين ناحيه و متعاقباً آلوده شدن آن و و
استافيلوكو كوس اورئوس يك كلونيزه كننده يوسـت و مخـاط اسـت كـهـ مـى توانـد باعـث طيـف كسـتردهاى از

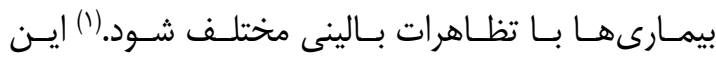
ميكروارگًانيسم از مهمترين عوامل عفونتهاى بيمارستانى

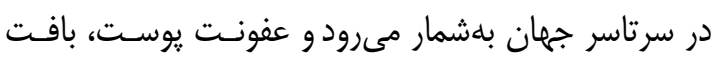
نرم، عفونت محل جراحى، عفونتهاى تنفسى تحتـانى از

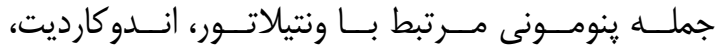
عفونتهاى ناشى از كاتترهاى عروقى، عفونت دريجههاى

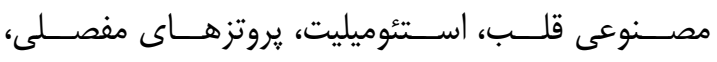

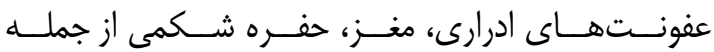


بيمارستانى تك تخصصى) به روش تصادفى خوشهاى (بـا استفاده از جدول اعداد تصادفى در زير خوشههـا) انتخـاب تضاب

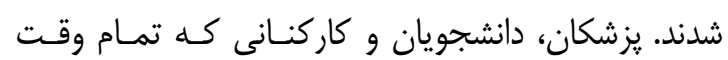
مشغول به كار نبودند، از مطالعه حذف شدندان

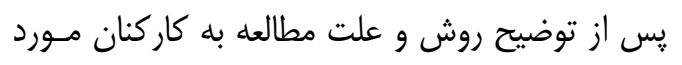

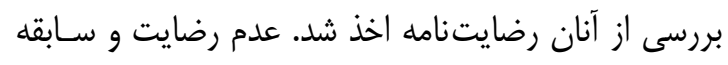

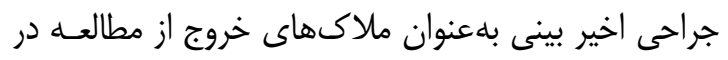

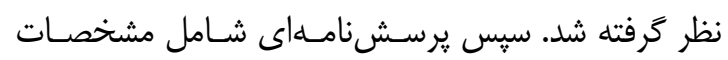

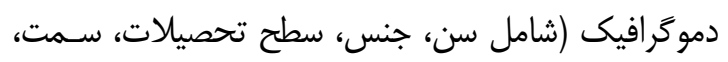
مدت سابقه كار، بخش محل خدمت، سابقه بيمارى خاص

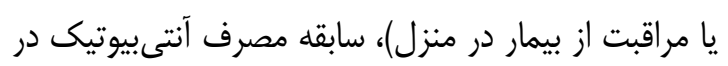

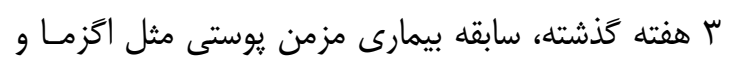

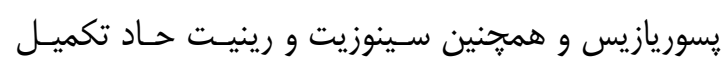

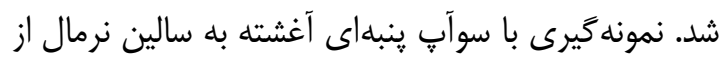

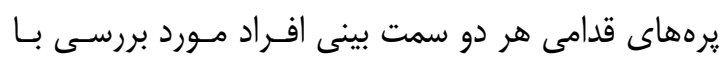

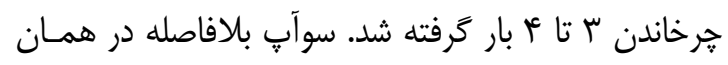

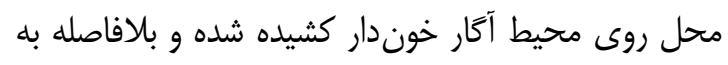

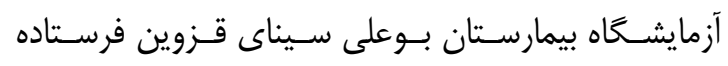

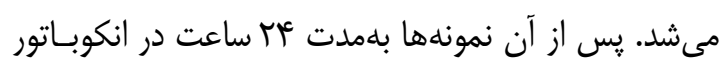

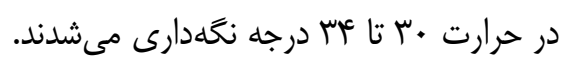

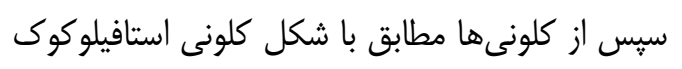

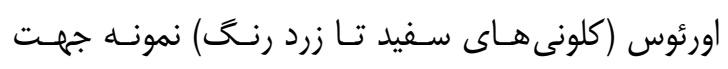

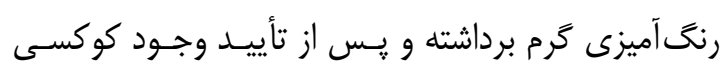

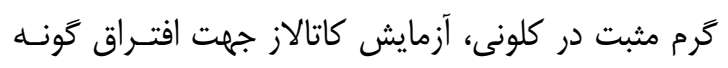

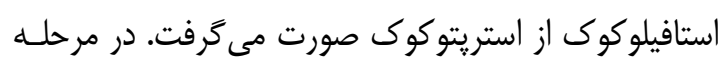

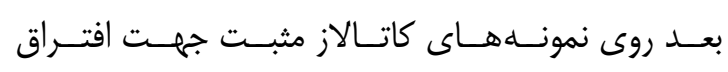
استافيلوكوى كوآَولاز مثبت (استاف اورئوس) از كوآكَ لاز

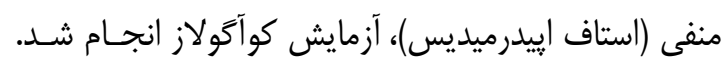

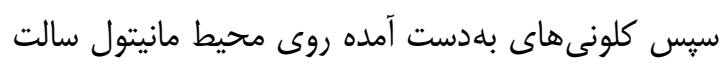

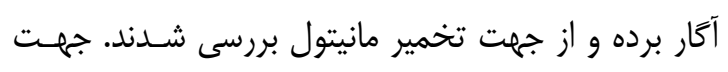

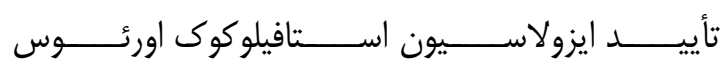
آزمونهاى DNAase و حساسيت به نووبيوسين هم انجام

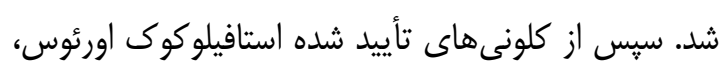

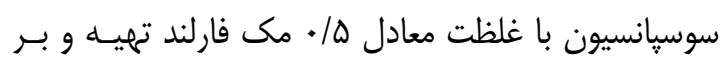

يا ساير وسايل به ديخــر افـراد از جملـه بيمـاران بسـترى

منتقل مىشود. مان ماير وسايل دئ

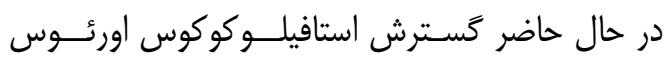

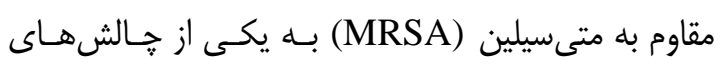

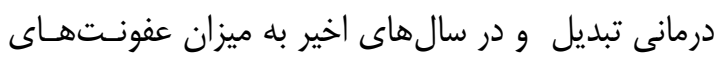
بيمارستانى ناشى از MRSA افزوده شده اسـت. (9) اكريـهـ بهنظر مىرسد كاركنان سلامت بلهطور شايع بلهعنوان ناقل عمل مى كنند و مخزن عمده MRSA نيستند، با اينحسال

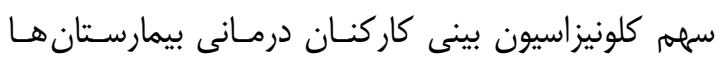

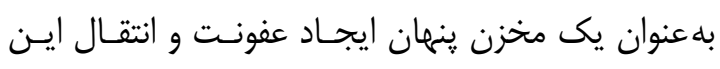

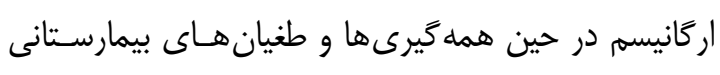

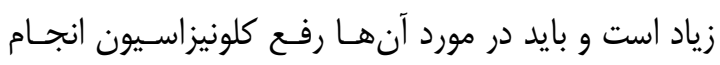

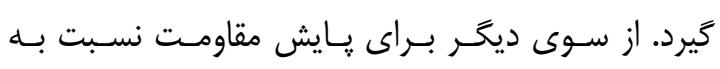

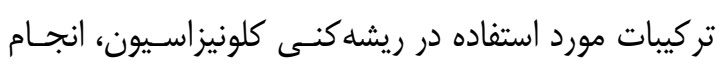

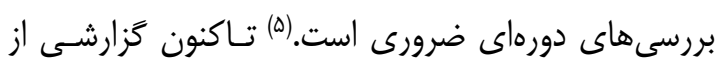

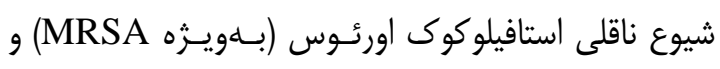

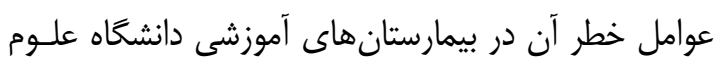

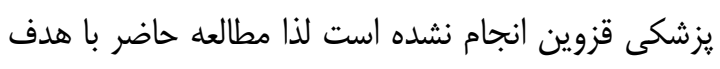

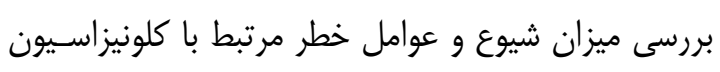

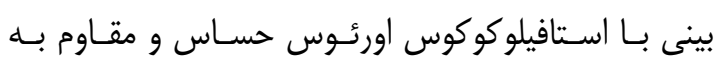

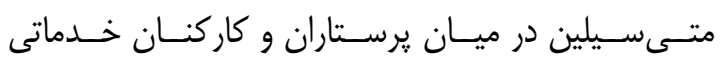
بخش هاى مختلف بيمارستان هاى آموزشى دانشخاه علـوم يزشكى قزوين انجام شده است.

\section{إن مواد و روشها:}

اين مطالعه مقطعى در فاصله مهــر هوسا تـا فـروردين

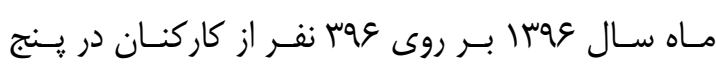

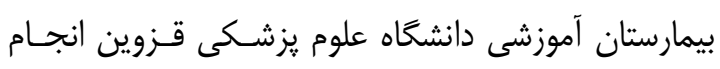

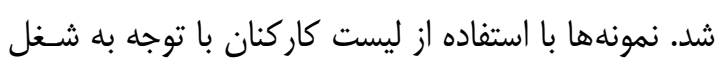

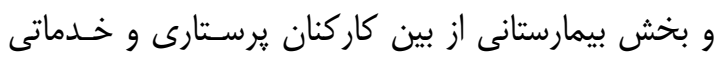

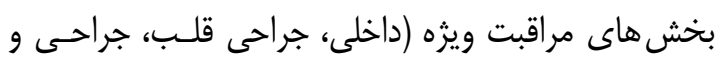

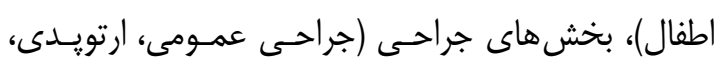

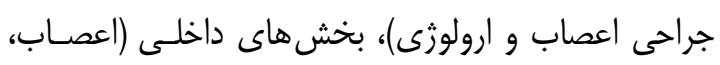

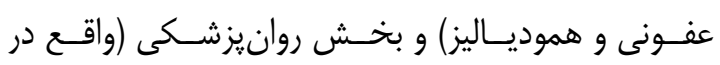


قطع مى كرد، خوانده مىشود.(9) بهعنوان معيـار حساسـيت

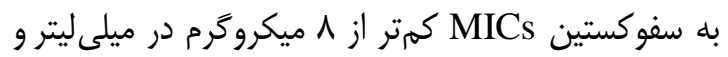

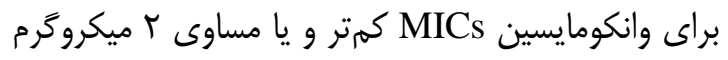
در ميلى ليتر در نظر گرفته شد. (^)

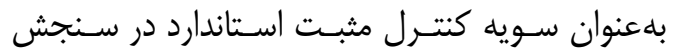
مقاومـت آنتى بيوتيكى از سويــــ aureus ATCC) 25923) American Typing Culture Collection استفاده شد. تجزيه و تحليل دادهها با استفاده از نـرمافـزار آمـارى سئس

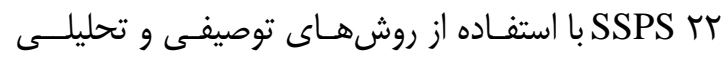

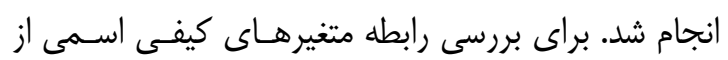
آزمون مجذور كاى و در مورد متغير سـطح تحصـيلات از راز

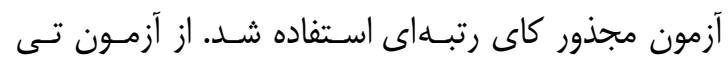
مستقل نيز براى مقايسه متغيرهاى كمى مانند سن استفاده شد. سطح معنى دارى كمتر از هـ ـ • در نظر كرفته شد.

\section{每}

در مجمـوع 191 نفر(حسدود •ه درصــ) از عوس نفــر

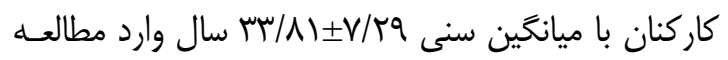
شدند. مشخصات دموكرافيك و سابقه ابتلاى اين كاركنان

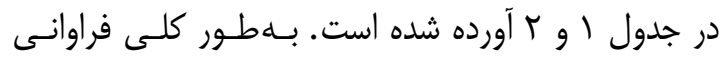

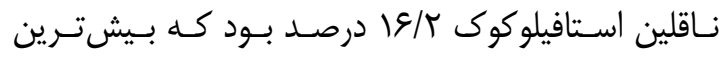

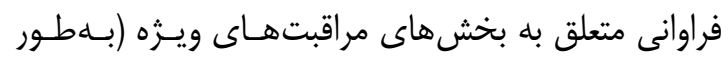

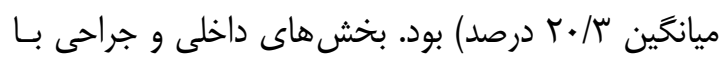

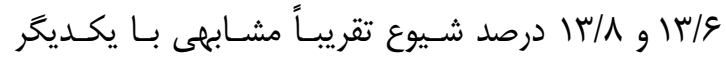

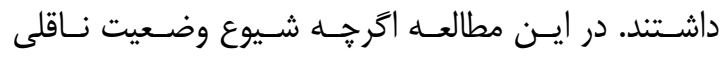

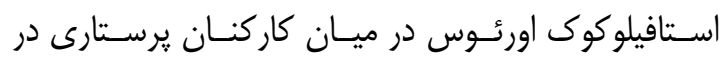

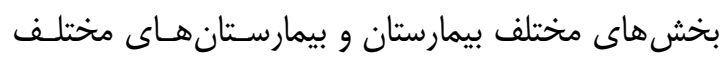

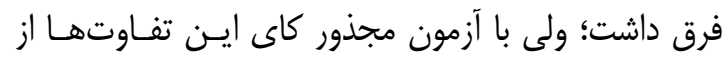

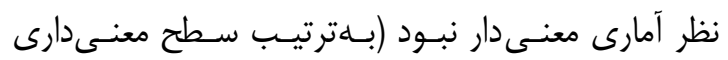

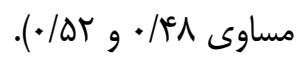

آزمون مجذور كاى نشـان داد كلونيزاسـيون بينـى بـاــاء

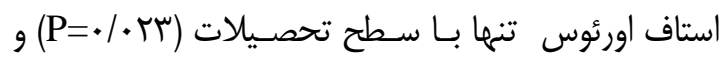

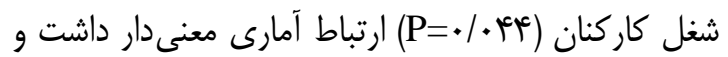

روى محيط كشت مولر هينتون أكًار برده شد. ديسكهاى

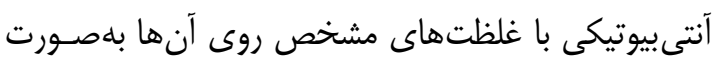

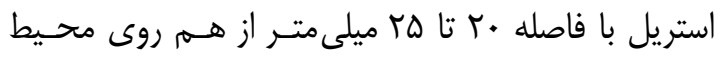

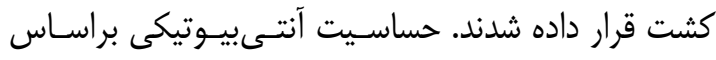

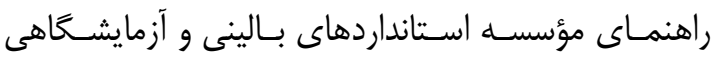

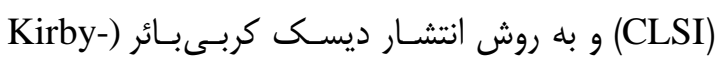

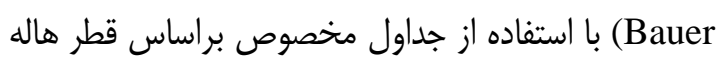
عدم رشد تعيين شد. (V) با توجه به اين كه طبق مطالعات انجـام شـده آزمـون

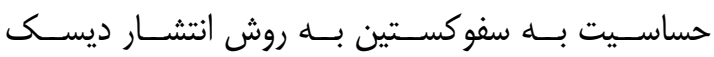
ارزش اخبارى منفى (cefoxitin disk diffusion test)

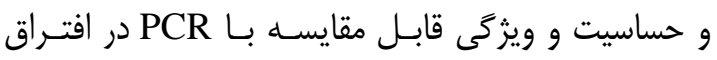

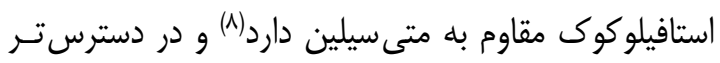

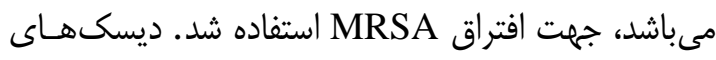

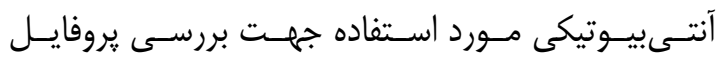

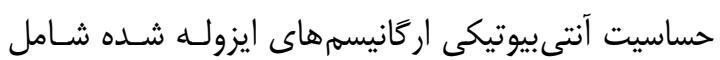

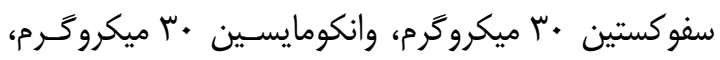

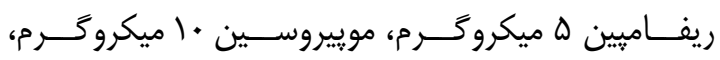

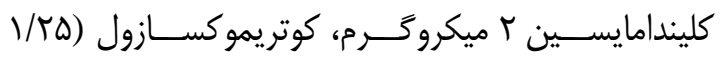

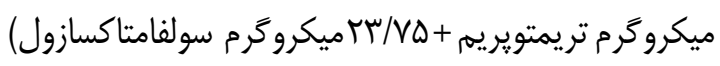

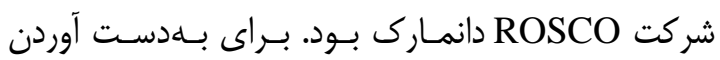

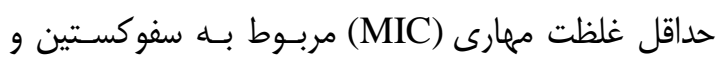

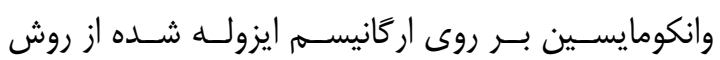
Liofilchem شـركـــــ (Epsilometer test) E-test ايتاليا استفاده شد. تيك نوار معرف آماده مصرف با يـك تراديـان

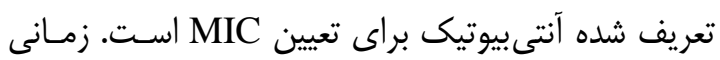

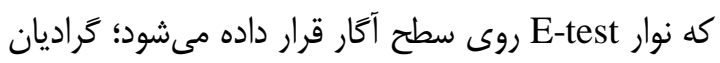

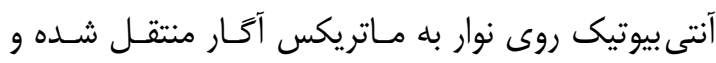

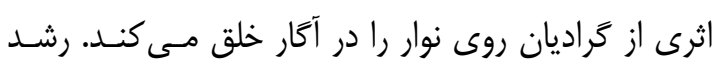

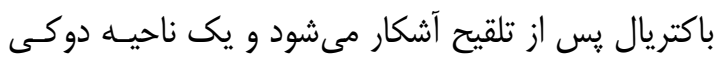

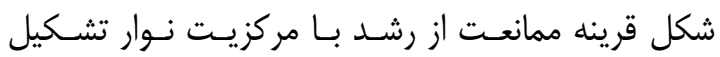

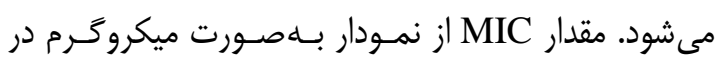

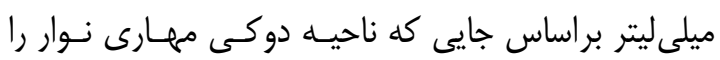


شده به كوتريموكسازول مقاوم بود. اين ايزوله نيز مقاومت

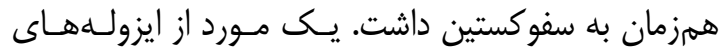

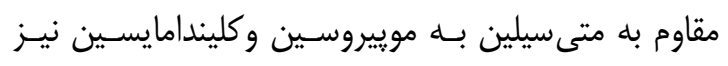

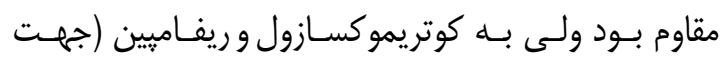

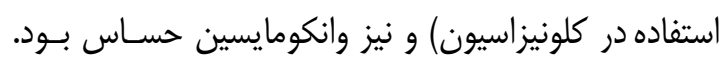

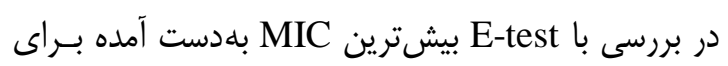

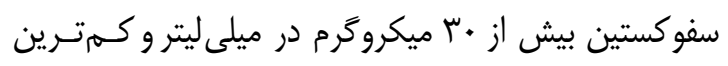

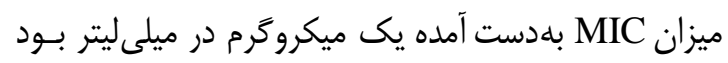

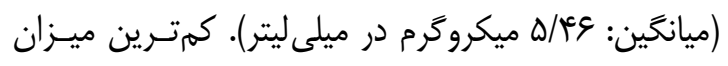

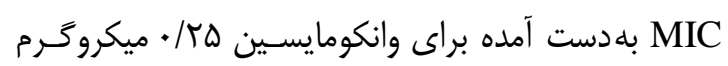

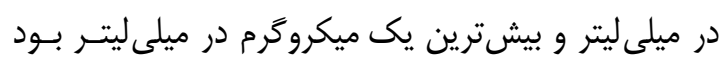

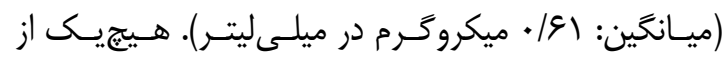
ايزولهها مقاوم به وانكومايسين نبودند (نمودار شماره ().
با متغيرهاى ديخر مانند سن و مدت زمان اشـتغال ارتبـاط

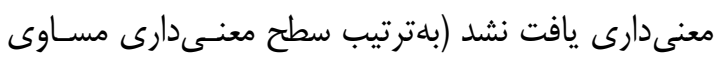

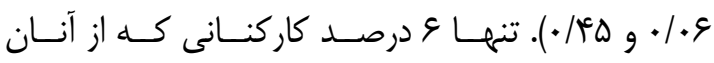

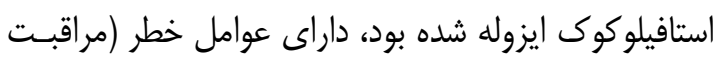

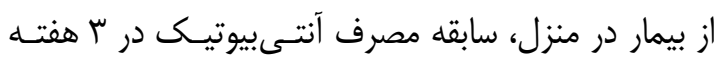

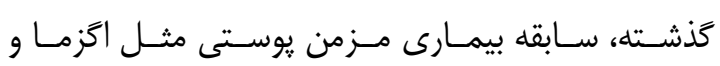

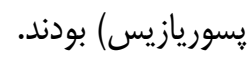

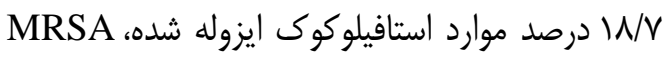

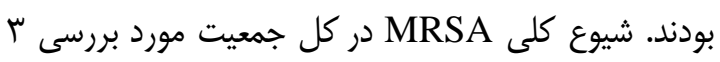

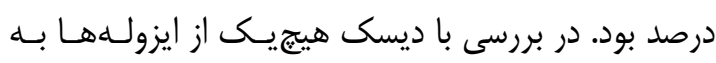

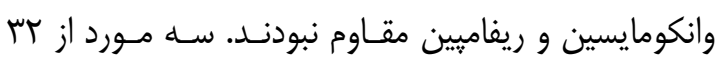

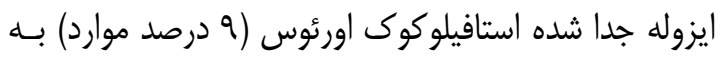

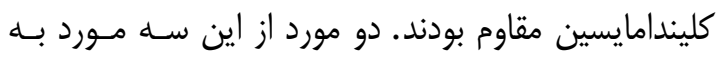

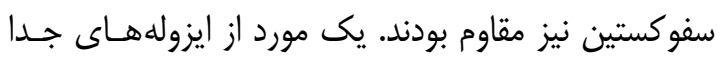

جدول ا - توزيع فراوانى ناقلين استافيلوكوكوس اورئوس برحسب متغيرهاى كيفى مورد بررسى

\begin{tabular}{|c|c|c|c|c|c|}
\hline \multirow{2}{*}{ سطح معنىدارى } & \multicolumn{3}{|c|}{ نتيجه كشت (درصد) تعداد } & \multirow{2}{*}{\multicolumn{2}{|c|}{ متغير مورد بررسى }} \\
\hline & مجموع - ل مجوع & مثبت & منفى & & \\
\hline \multirow{2}{*}{$\cdot / \cdot r$} & te $(K / T)$ & $11(K r / F)$ & ra (rI/I) & مرد & \multirow{2}{*}{ جنسيت } \\
\hline & $\operatorname{lQT}(V \varepsilon / \Lambda)$ & TI $(\xi \Delta / \&)$ & וזו (VN/q) & زن & \\
\hline \multirow{3}{*}{ 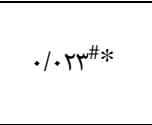 } & $\Delta \Gamma(T \& / \Lambda)$ & $1 \pi(\xi \cdot / q)$ & $F \cdot(Y \leftarrow / I)$ & دييلمم و يايينتر & \multirow{3}{*}{ سطح تحصيلات } \\
\hline & $\operatorname{lrf}(g V / V)$ & $19(\Delta 9 / 4)$ & $110(99 / \mu)$ & كارشناسى & \\
\hline & $11(\Delta / 8)$ & . & $11(8 / 8)$ & كارشناسى ارشد & \\
\hline \multirow{2}{*}{.$/$. reck } & $\operatorname{lic}(\mathrm{Vr} / \mathrm{V})$ & $19\left(\Delta q / T^{c}\right)$ & $\operatorname{IrV}(V \& / Q)$ & يرستار & \multirow{2}{*}{ شغل } \\
\hline & $\Delta T(r \varepsilon / \Gamma)$ & $I r(\% \cdot / \varepsilon)$ & rq $(r / \Delta / \Delta)$ & كاركنان خدماتى & \\
\hline \multirow{5}{*}{.$/ 019$} & $99(\Gamma \Delta)$ & $I r(\xi \cdot / \varepsilon)$ & $\Delta f(r r / q)$ & بوعلى & \multirow{5}{*}{ بيمارستان } \\
\hline & Gr (rY/Q) & $V(r / / q)$ & $\Delta \Delta(\Psi \Gamma / \Gamma)$ & شهيد رجايى & \\
\hline & $\mathrm{rV}(\mathrm{IN} / \Lambda)$ & $\Lambda(\Gamma \Delta)$ & rq (IV/9) & ولايت & \\
\hline & $\operatorname{lf}(\mathrm{V} / \mathrm{I})$ & $1(\mu / 1)$ & $1 \%(V / q)$ & قدس & \\
\hline & $10(V / 9)$ & $r(q / f)$ & $I r(V / r)$ & rابجهن & \\
\hline \multirow{3}{*}{$\cdot / 4 V q$} & $V \mathcal{E}(r V / \mathcal{F})$ & $10(\$ 8 / 9)$ & $\Delta q(\Gamma \Delta / \Delta)$ & ICUs & \multirow{3}{*}{ بخش } \\
\hline & $\Delta q(r q / \wedge)$ & $\Lambda(\Gamma \Delta)$ & $\Delta)(r \cdot / V)$ & داخلى & \\
\hline & $9 \Delta(T Y / \Lambda)$ & $9(T N / I)$ & $\Delta \mathcal{D}(\mathrm{H} / \mathrm{V})$ & جراحى & \\
\hline \multirow{2}{*}{.$/ 1 T \Delta$} & $19 \Lambda(\Lambda F / \Lambda)$ & r. (१५/^) & I & منفى & \multirow{2}{*}{ سابقه مصرف آنتىبيوتيك } \\
\hline & $r \cdot(I Q / Y)$ & $r(\varepsilon / \mu)$ & $r \wedge(1 \varepsilon / 9)$ & مثبت & \\
\hline \multirow{2}{*}{$\cdot / I Q F$} & $1 M(9) / 9)$ & $r r(1 \cdot \cdot)$ & $109(95)$ & منفى & \multirow{2}{*}{ سابقه بيمارى هاى يوستى } \\
\hline & $1 \cdot(\Delta / 1)$ & $\cdot$ & $1 \cdot(9)$ & مثبت & \\
\hline \multirow{2}{*}{ Trt } & $194(9 \mathrm{~V} / 0)$ & $r r(1 \cdot \cdot)$ & $191(9 \mathrm{~V})$ & منفى & \multirow{2}{*}{ تماس خانگى } \\
\hline & $\Delta(T / \Delta)$ & $\cdot$ & $\Delta(r)$ & مثبت & \\
\hline \multirow{2}{*}{ •/VAD } & $\operatorname{IVE}(\Lambda N / q)$ & $r \wedge(\Lambda V / \Delta)$ & $1 \leftarrow \wedge(\wedge q / T)$ & منفى & \multirow{2}{*}{ آبريزش بينى حاد } \\
\hline & tr(II/I) & $F(I r / \Delta)$ & $1 \wedge(1 \cdot / \Lambda)$ & مثبت & \\
\hline
\end{tabular}


جدول r- توزيع فراوانى ناقلين استافيلوكوكوس اورئوس برحسب متغيرهاى كمى مورد بر رسى

\begin{tabular}{|c|c|c|c|c|}
\hline سطح معنىدارى & انحراف معيار土ميانكين & تعداد & نتيجه كشت & متغير (سال) \\
\hline \multirow{2}{*}{.1 .91} & $r / / F V \pm V / \Delta q$ & 199 & منفى & \multirow{2}{*}{ سن } \\
\hline & $r \Delta / \Delta \xi \pm \Delta / r \mu$ & rT & مثبت & \\
\hline \multirow{2}{*}{. A4E } & 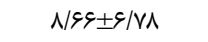 & 199 & منفى & \multirow{2}{*}{ مدت زمان اشتغال } \\
\hline & $q / \varsigma q \pm \varnothing / \vee \wedge$ & ru & مثبت & \\
\hline \multirow{2}{*}{.$/ 9 \vee \wedge$} & $F / \backslash \varphi \pm \Psi / \mathscr{A} V$ & 199 & منفى & \multirow{2}{*}{ مدت اشتغال در بخش موردنظر } \\
\hline & $r / N E \pm r / V e$ & rT & مثبت & \\
\hline
\end{tabular}

نمودار ا - مقايسه ميزان كلونيز اسيون استافيلوكوكى كار كنان درمانى برحسب سطح تحصيلات و شغل

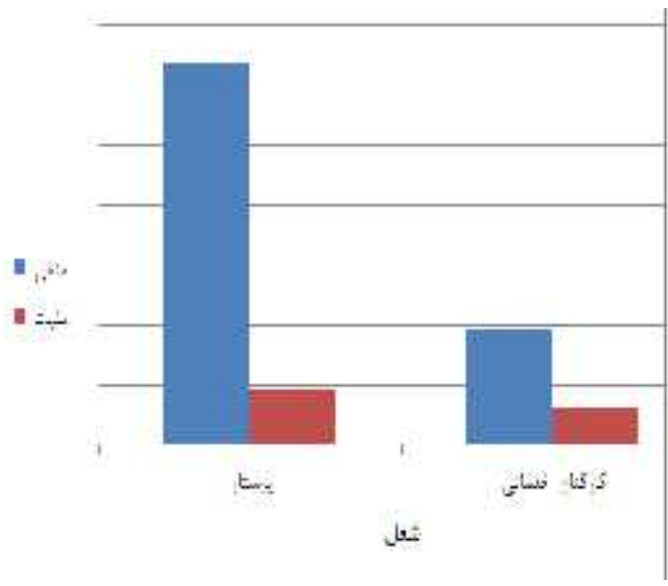

تفاوت در رعايت اصول بهداشتى در بـين كاركنـان مـورد

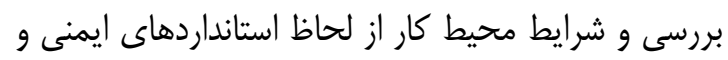

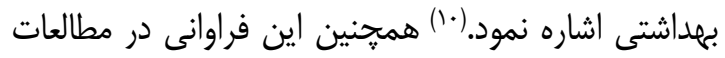

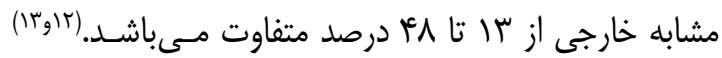

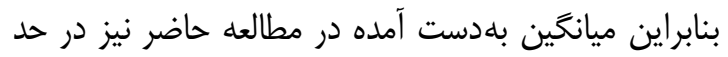
קايين متوسط محسوب مى شود. در مقايسه نتايج مطالعات

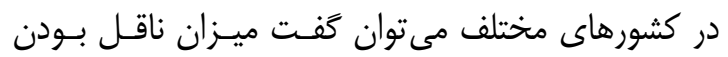
استافيلوكوك در كاركنان درمانى بسته بــهـ كشـور، زمينـهـ

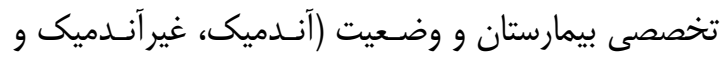

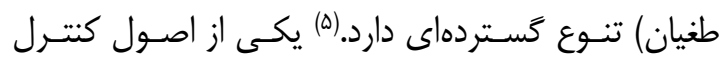

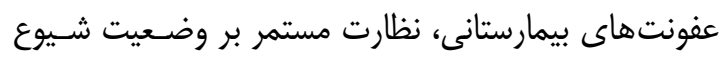
ميكرواركانيسه هاى موجود در بيمارستان، شناسايى عوامل بئل

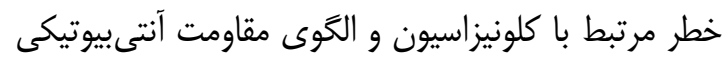

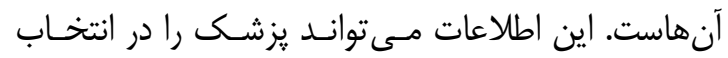

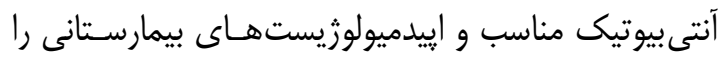

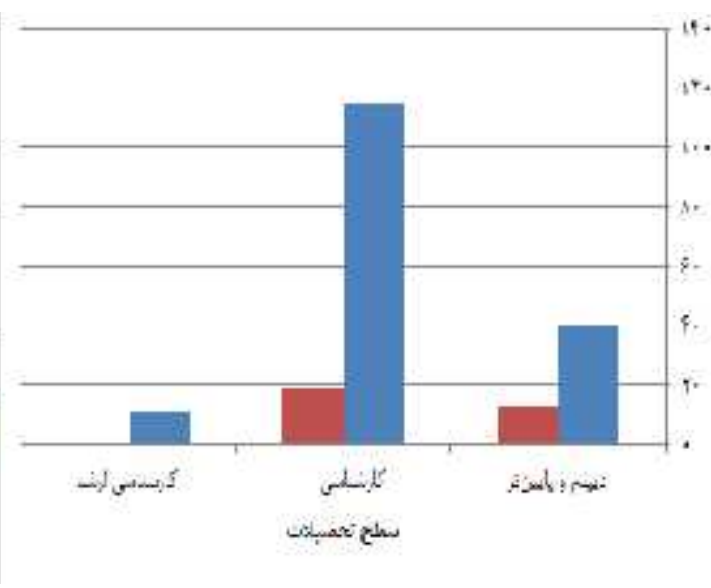

بحث و نتيجل

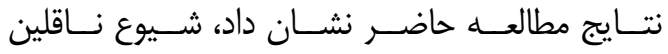

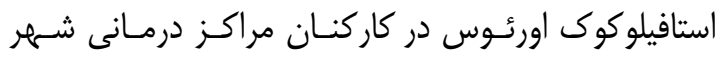

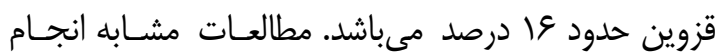

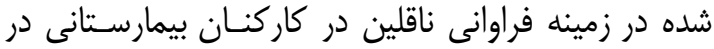

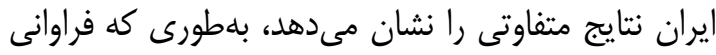

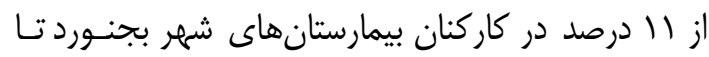

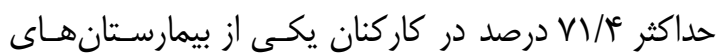

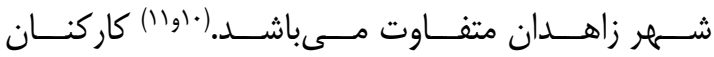

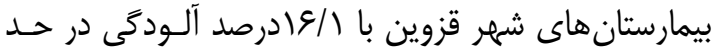

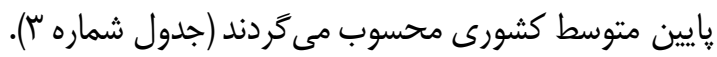

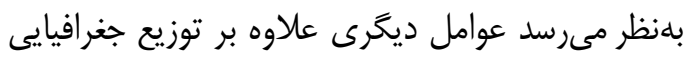

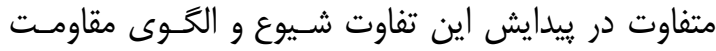

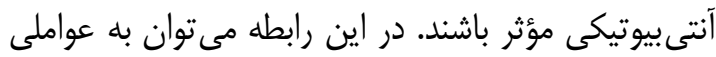

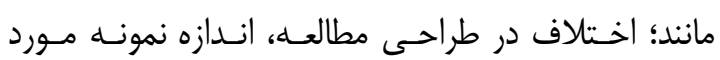

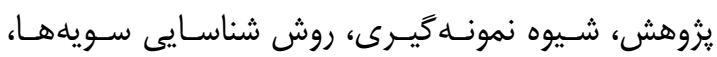


تا عث درصد است. (IVIT)

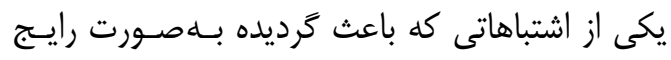

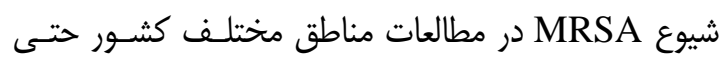

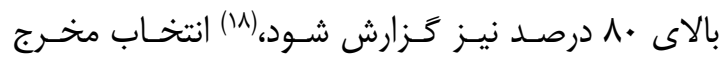

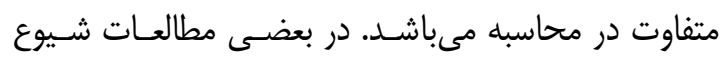
بهعنوان تعداد MRSA نسبت به كل سويههاى جدا شده

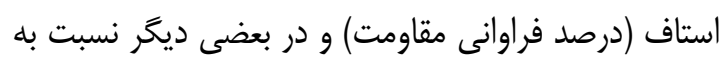

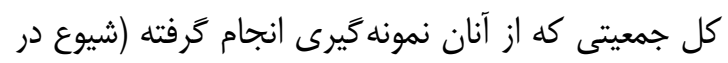

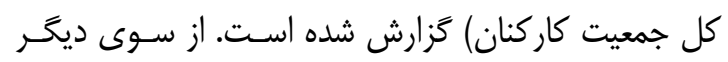

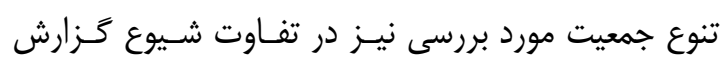

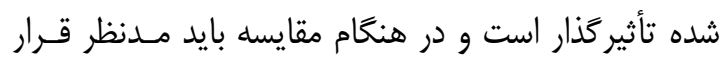

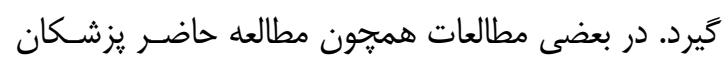

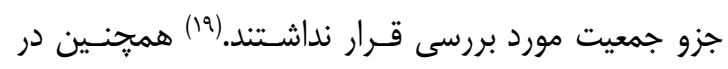

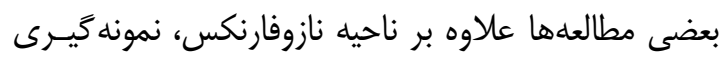

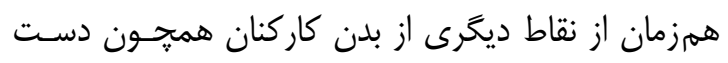

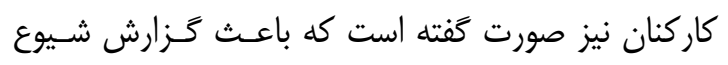

$$
\text { بيشتر كرديده است.. (r) }
$$

در مشخص كردن سياستهاى درست كنترل عفونتهاى بيمارستانى يارى دهد.(IF)

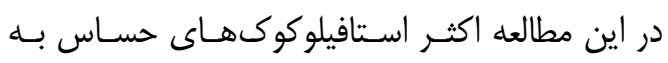

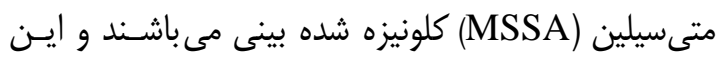

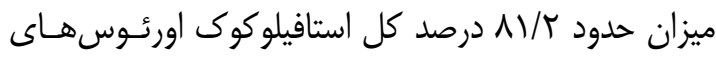

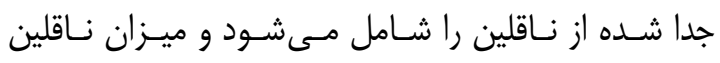

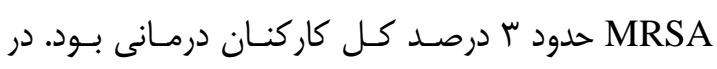

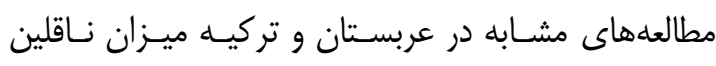

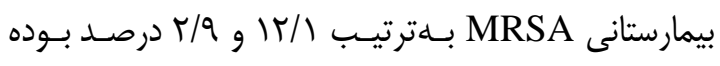

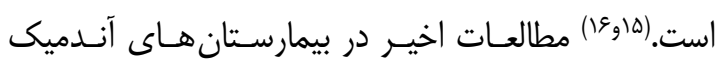

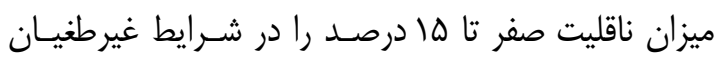

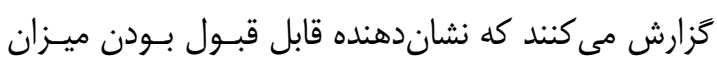

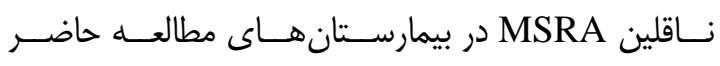

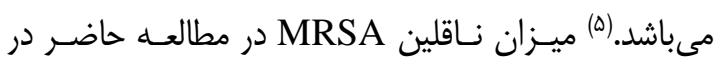

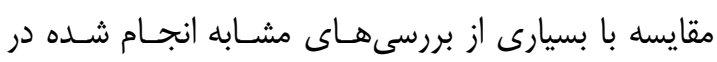

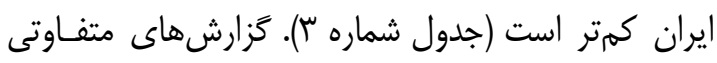

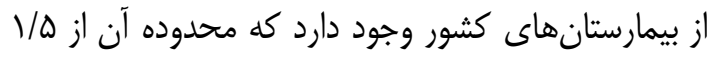

جدول بـ- توزيع فراوانى ناقلين استافيلوكوكوس اورئوس و التَوى مقاومت در كار كنان مراكز درمانى نقاط مختلف در ايران

\begin{tabular}{|c|c|c|c|c|c|c|c|}
\hline \multicolumn{3}{|c|}{ مقاومت (تعداد) } & \multirow{2}{*}{ 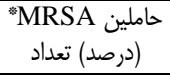 } & \multirow{2}{*}{ 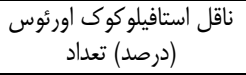 } & \multirow{2}{*}{ تعداد } & \multirow{2}{*}{ سال انجام } & \multirow[t]{2}{*}{ محل انجام مطالعه' } \\
\hline موي - مويروسين & ريفامبين & وانكومايسين & & & & & \\
\hline$\cdot$ & - & - & $\Lambda \Delta(1)$ & $\left.\mu^{*}\right)(\mu / T)$ & $W^{c}$ & $\mid \overline{|r \Lambda|}$ & تهران (T) \\
\hline- & f & (VISA) 9 ، (VRSA) r & بررسى نشد & 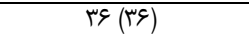 & $1 \ldots$ & THAT & قائم شهر (IM) \\
\hline- & - & (VRSA) I & i) (IV) & VY $(Y T / Q)$ & Te. & TMAT & 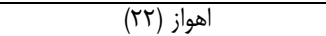 \\
\hline- & - & $\cdot$ & rq (\$8) & $F \Delta(V \backslash / \mathscr{C})$ & gr & ITNA & زاهدان (TI) \\
\hline . & 1 & (VISA) 1 & r $(\Delta / \mu)$ & $\mid M g(r \backslash)$ & $9 . \cdot$ & Ir & شيراز (19) \\
\hline- & - & - & بررسى نشد - مبل & $9 \Delta(T \Delta / \Lambda)$ & TAT & INAD & مركز بعثت نيروى هوايى ارتش (T) \\
\hline- & - & - & $\Delta \mathrm{V}(\mathrm{V} / \mathrm{V})$ & $9 f(I T / V)$ & VET & IT & يزد (T) \\
\hline- & - & $\cdot$ & $1 \cdot(\Gamma)$ & $\Lambda \cdot\left(Y^{\mathrm{C}}\right)$ & Trו & $I T M$ & كركان (r.) \\
\hline- & - & - & - & $r \cdot(\Gamma / \Delta)$ & $11 \pi$ & ITM & تبريز (TQ) \\
\hline 1 & - & - & rq (1)/1) & $V \cdot(T V)$ & TEI & 1419 & 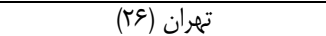 \\
\hline$\cdot$ & f & $\cdot$ & $\Lambda(\varphi / \mathcal{q})$ & Fi $(T, Y)$ & $\mathrm{IV}^{\mu}$ & $14 \wedge 9$ & اردبيل (TV) \\
\hline- & - & $(\mathrm{VRSA}){ }^{\mathrm{F}}$ & $19(10 / \Lambda)$ & MF $(T \Lambda / T M)$ & $\pi r$. & 1419 & تنكابن (Yی) \\
\hline- & - & (VISA) )، (VRSA) I & $18(\Delta, r \mu)$ & $g r(r \backslash / r)$ & 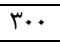 & 1\%q. & خرم آباد (qr) \\
\hline- & $r$ & $(\mathrm{VRSA}) \Delta$ & $9(T / T)$ & $F \Delta(11 / \%)$ & rqv & 1491 & جهرم (r. \\
\hline- & - & $(\mathrm{VRSA}){ }^{r}$ & $9(1 / 0)$ & $\Lambda \varepsilon(1 F / 9)$ & 091 & 1199 & شيراز (IV) \\
\hline$\Delta$ & 1 & $\cdot$ & $\operatorname{IV}(\varepsilon / \mu)$ & $r q(I f / F r)$ & $r V \cdot$ & Irat & تهران (rا) \\
\hline- & - & - & $1 \%(1 \cdot / \Lambda)$ & TA $(T \backslash / \Delta)$ & 14. & ITat & تربت حيدريه (Tr) \\
\hline- & $\cdot$ & $\cdot$ & $r(1 / \Delta)$ & $r(11)$ & $r \cdot \cdot$ & 1495 & بجنورد (II) \\
\hline & & & $\pi(11 / \%)$ & $\Delta \Gamma(T \Delta / \Delta)$ & 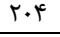 & 14ar & شهركرد (Tr) \\
\hline- & - & . & $14(\mathrm{~V} / \mathrm{I})$ & $r \Lambda(19 / 4)$ & 198 & 1199 & سارى (ז' (ז) \\
\hline$r$ & $\Delta$ & - & $\operatorname{IV}(1 \cdot, \Lambda T)$ & $\Gamma \wedge\left(T \Delta, \Gamma^{\top} \wedge\right)$ & $I \Delta V$ & $1 \% 90$ & تهران (سّ) \\
\hline 1 & $\cdot$ & $\cdot$ & $9(\Gamma)$ & rr (Ig/I) & 191 & 1190 & قزوين (مطالعه حاضر) \\
\hline
\end{tabular}

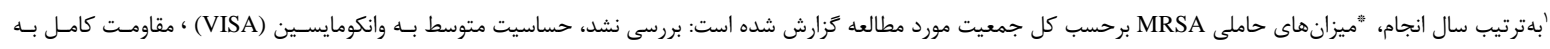




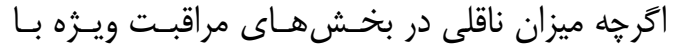

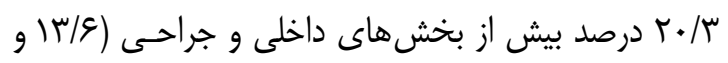

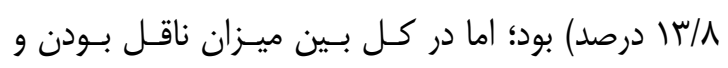

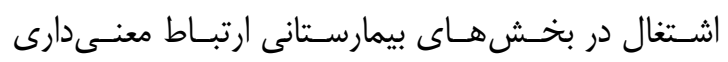

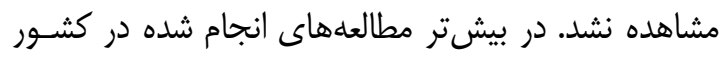

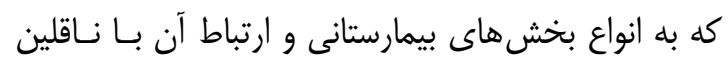

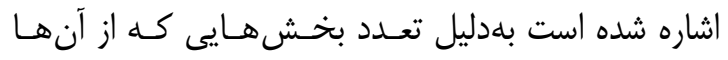

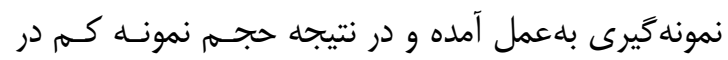

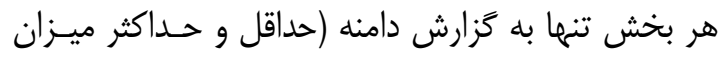

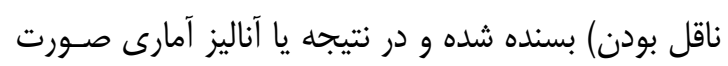

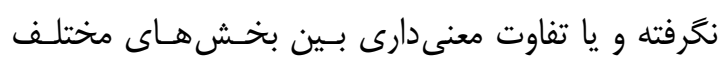

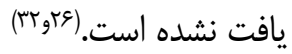

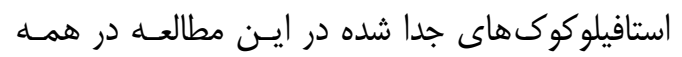

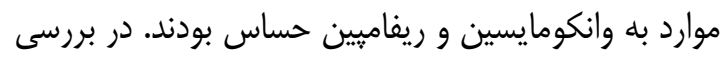

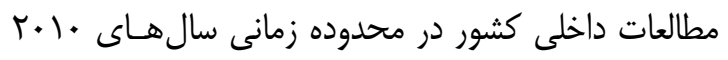

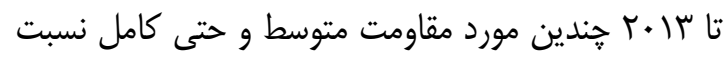

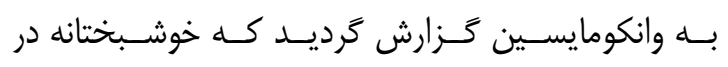
سال هاى بعـــ در مطالعـات داخلـى در ايسن زمينـه مـورد

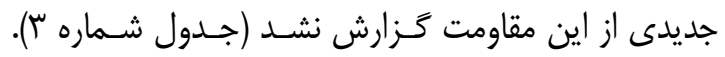

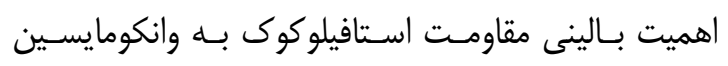
زا (Intermediate: VISA, resistant: VRSA) آنجاست كه در صورت عفونت با اين اركانيسمها درمـان با وانكومايسين موفق نخواهد بود. در اين سال ها موارد مقاومت نسبت به مويبيروسـين و وند بودي

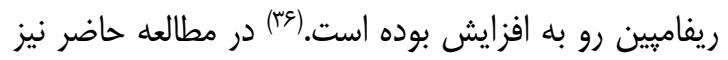

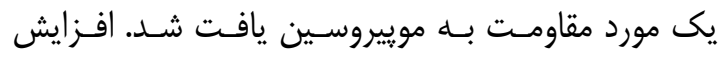
مقاومت نسبت به ريفاميين و موييروسين بلهويزه بـهـ ايسن مونـ

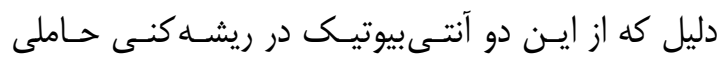

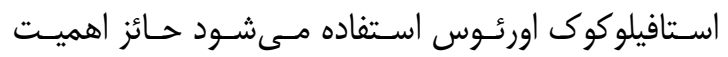

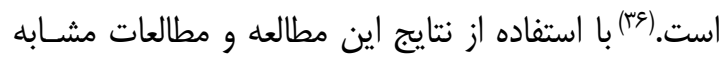
مىتوان نتيجه كيرى نمود كه ادامه رزيمهاى فعلى مـورد إنى

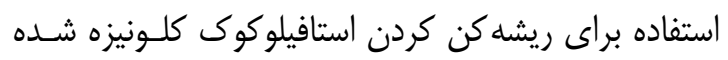

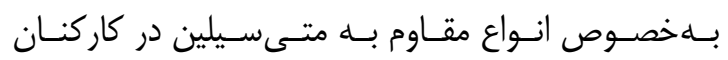

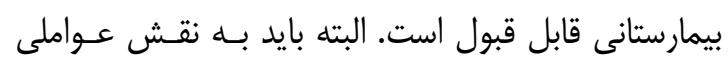

در اين مطالعه از نظر (سن، جنس و مــدت اشـتغال) و

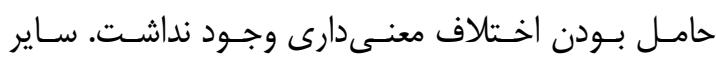

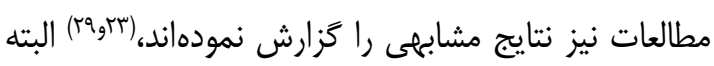
در بعضى مطالعات افزايش ميزان فراوانى حاملين در سنين

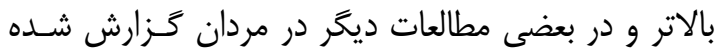

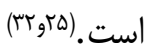

در مطالعـه حاضـر شــيوع ميـزان فراوانسى حــاملين

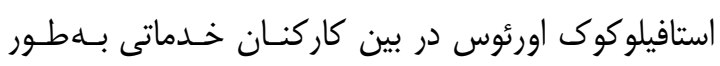

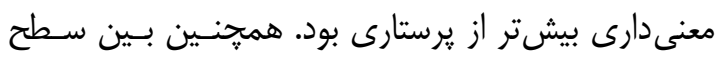

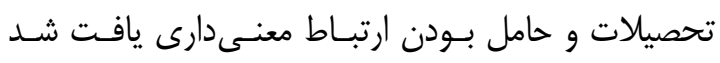
بلهورى كه با افزايش سطح تحصـيلات، ميـزان فراوانى إنى

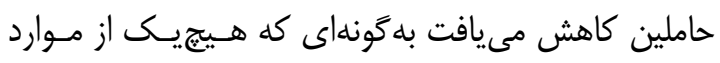

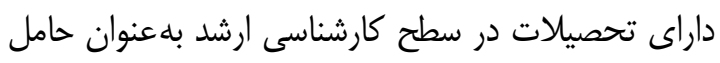

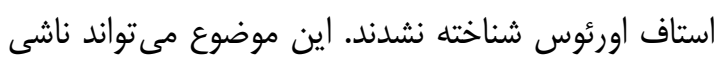

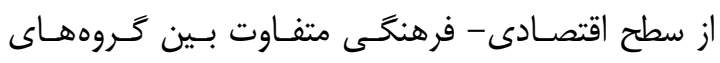

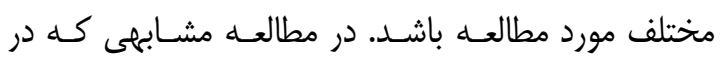

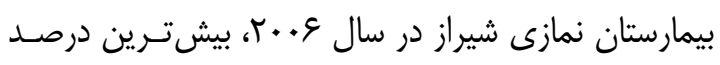

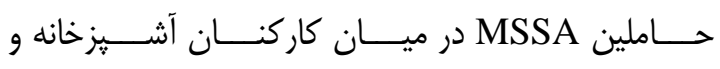

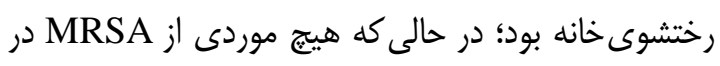

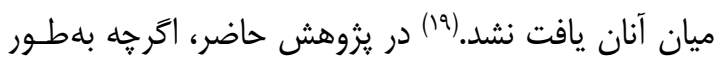

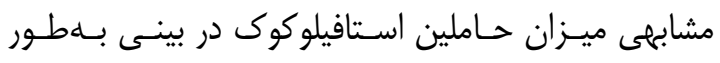

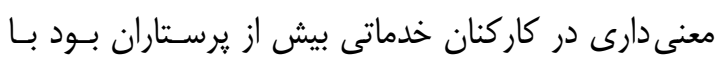

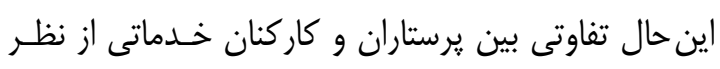

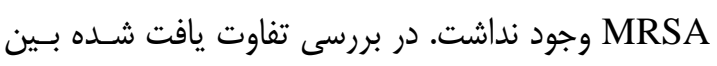

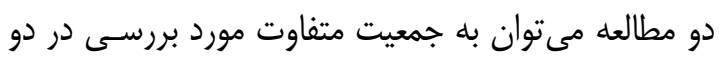

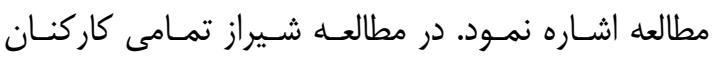

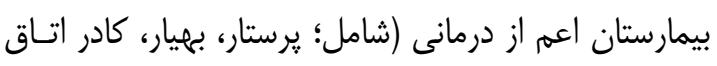

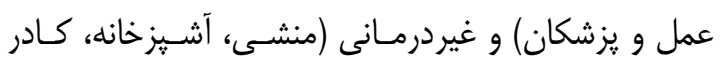

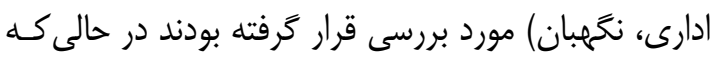

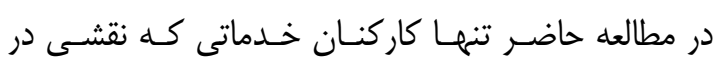

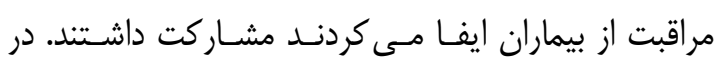

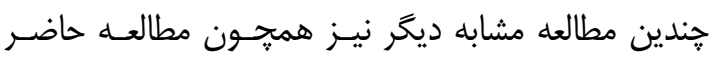

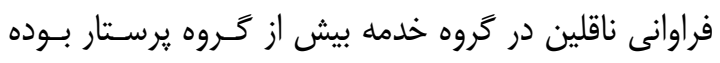

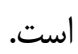


MRSA

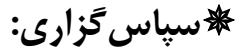

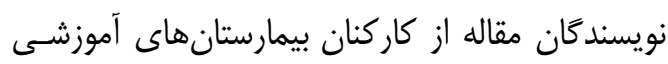

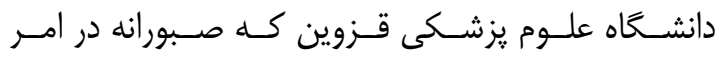
نمونه گيرى مساعدت و يارى رساندند و همجنين خانم نير

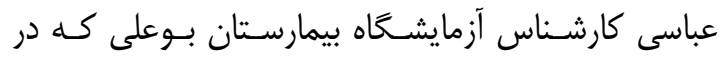

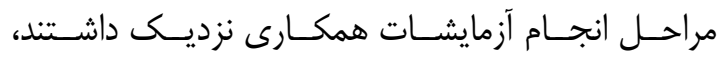
سباس گزارى نموده و همجنين از معاونت محترم يزوهش إن دانشعاه جهت تأمين هزينهـــاى طـرح، صـميمانه تشـكر

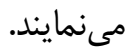
اين مقاله حاصل קايان نامـهـ دكتـر سـيده سـارا نـاظهم ساداتى دستيار بيمارىهاى عفونى دانشگاه علوم يزشكى داصى

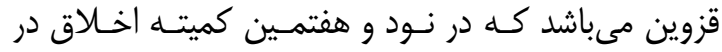
يزوهش هاى زيست يزشكى دانشكاه علوم يزشكى قزوين

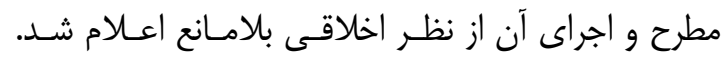

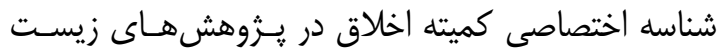
IR.QUMS.REC.1395.147 يزشكى براى اين مطالعه مىباشد.

\section{:مراجع:}

1. Chambers HF, Deleo FR. Waves of resistance: Staphylococcus aureus in the antibiotic era. Nat Rev Microbiol 2009; 7(9): 629-41. doi: 10.1038/nrmicro2200.

2. Albrich WC, Harbarth S. Health-care workers: Source, vector, or victim of MRSA? Lancet Infect Dis 2008; 8(5): 289-301. doi: 10.1016/S1473-3099(08)70097-5.

3. Tong SY, Davis JS, Eichenberger E, Holland TL, Fowler VG Jr. Staphylococcus aureus infections: epidemiology, pathophysiology, clinical manifestations, and management. Clin Microbiol Rev 2015; 28(3): 603-61. doi: 10.1128/CMR.00134-14. 4. Holland T, Fowler VG. Clinical manifestations of Staphylococcus aureus

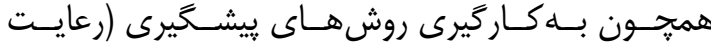
احتياطات همه جانبه و شستن دستهـا) در كنـار درمـان

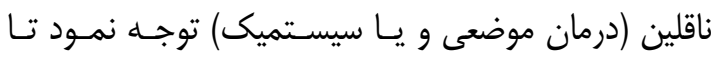

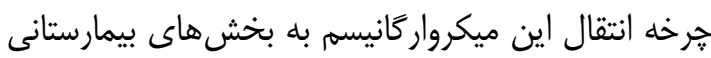
كاهش دادو در نهايت عفونتهاى مر خبار اسـتافيلوكوكى إنى بيمارستانى را كنترل نمود.(·)

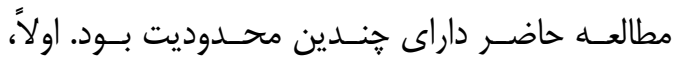

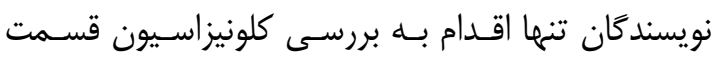

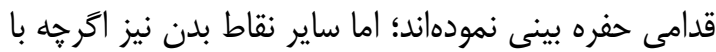
شيوع كمتر مىتواند در انتقال اسـتافيلوكوك بــه بيمـاران

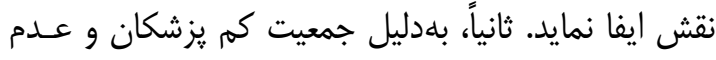

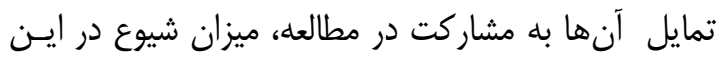
زير گروه مشخص نخرديد. ييشنهاد مى گردد در مطالعات

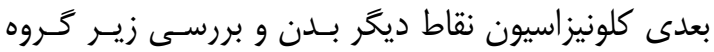

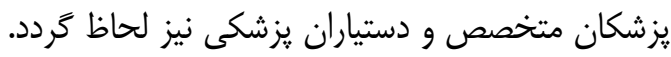

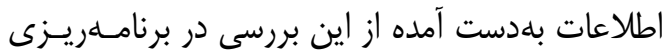
اقدامات كنترل عفونت بيمارستانى در سطح دانشخاه علوم

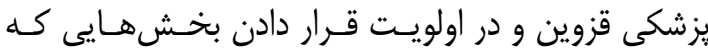

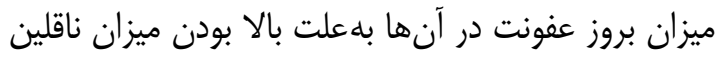

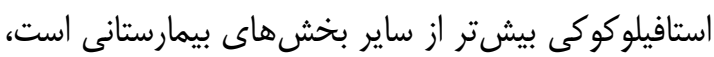

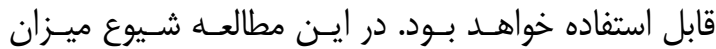
فراوانى حاملين عفونست اسـافيلوكوكى در بـين كاركنـان

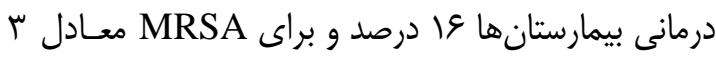
درصد محاسـبه شـد. ميـزان فراوانسى بـا شـغل و ســـانح تحصيلات كاركنان ارتباط داشت و بهنظر مىرسد آموزش كاركنان در سطوح يايينتر شـغلى و تحصـيلى در كـاهش

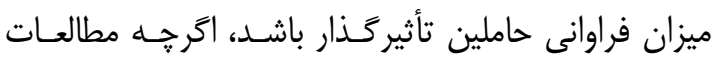

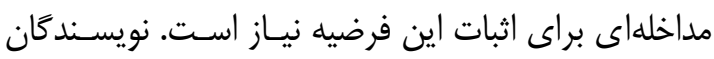
توصيه مى كنند كه جهت بررسى دقيـقتـر شـيوع ميـزان فراوانى حاملين استافيلوكوك اورئوس (بهويثه MRSA) و

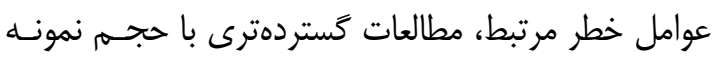

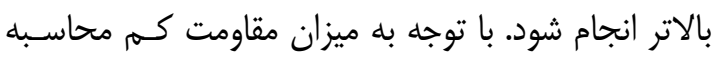
شده براى ريفامبين و موييروسين، اين دو جهت ريشه كنى كلونيزاسيون استاف در كاركنـان درمانس حتى در مـوارد 
infection in adults. https://www.uptodate.com Updated in: 2017.

5. Hawkins G, Stewart S, Blatchford O, Reilly J. Should healthcare workers be screened routinely for meticillin-resistant Staphylococcus aureus? A review of the evidence. J Hosp Infect 2011; 77(4): 285-9. doi: 10.1016/j.jhin.2010.09.038.

6. Anderson DJ. Methicillin-resistant Staphylococcus aureus (MRSA) in adults: Epidemiology. https://www.uptodate.com Updated in: 2018.

7. Cockerill FR, Wikler MA, Bush K, Dudley MN, Eliopoulos GM, Hardy DJ, et al. Clinical and laboratory standards institute. Performance standards for antimicrobial susceptibility testing; twenty-second informational supplement. CLSI document m100-s22. Wayne: Clinical and laboratory standards institute 2012; 32(3): 70-87.

8. Freeman J, Morris A. Rapid detection of methicillin-resistant Staphylococcus aureus. https://www.uptodate.com Updated in: 2017. 9. Hsu DI, Hidayat LK, Quist R, Hindler J, Karlsson A, Yusof A, et al. Comparison of method-specific vancomycin minimum inhibitory concentration values and their predictability for treatment outcome of meticillin-resistant Staphylococcus aureus (MRSA) infections. Int J Antimicrob Agents 2008; 32(5): 378-85. doi: 10.1016/j. ijantimicag.2008.05.007.

10. Ghafouri M, Besharati R, Lashkardoost H, Nojoomi S, Shakeri A, Shahasavand Sh. Prevalence of nasal carrier Staphylococcus aureus and their antibiotic resistance patterns among health care working in Bojnurd imam Reza hospital. J North Khorasan Univ Med Sci 2014; 6(1): 111-5 doi: 10.29252/jnkums. 6.1.111. [In Persian]
11. Alavinaeini R, Darvishi M, Izadi M, Ilami $\mathrm{O}$, Hatami H. The frequency and drug resistance of Staphylococcus areus nasocarriers in surgical staff and control group. Iran J Infect Dis Trop Med 2005; 10(31): 436.

12. Vinodhkumaradithyaa A, Uma A, Shirivasan M, Ananthalakshmi I, Nallasivam P, Thirumalaikolundusubramanian P. Nasal carriage of methicillin-resistant Staphylococcus aureus among surgical unit staff. Jpn J Infect Dis 2009; 62(3): 228-9.

13. de Carvalho MJ, Pimenta FC, Hayashida M, Gir E, de Silva AM, Barbosa CP, et al. Prevalence of methicillin-resistant and methicillin-susceptible S.aureus in the saliva of health professionals. Clinics (Sao Paulo) 2009; 64(4): 295-302. doi: 10.1590/S180759322009000400005.

14. Edmond MB, Wenzel RP. Organization for infection control. In: Bennett JE, Dolin R, Blaser MJ, editors. Mandell, douglas, and bennett's principles and practice of infectious diseases. 2: Philadelphia, 8th ed, Elsevier Health Sciences; 2014. 3669-72.

15. Abdulhaq A, Swaid AI, Al-Amoudi M, Marwan AM, Ayoub AM, Khamis AFA-D, Holba SA, et al. Prevalence of nasal carriage of methicillin-resistant Staphylococcus aureus among health care workers in a tertiary care hospital, Jazan province, kingdom of Saudi Arabia. Life Sci J 2016; 13(12):93-9. doi:10. 7537/marslsj131216.13. 16. Oguzkaya-Artan M, Baykan Z, Artan C, Avsarogullari L. Prevalence and risk factors for methicillin resistant Staphylococcus aureus carriage among emergency department workers and bacterial contamination on touch surfaces in Erciyes university hospital, Kayseri, Turkey. Afr 
Health Sci 2015; 15(4): 1289-94. doi: 10.4314/ahs.v15i4.31.

17. Saadat S, Solhjoo K, Norouz-Nejadfard MJ, Kazemi A, Rouhi R, Mardaneh J. The frequency of Staphylococcus aureus among Shiraz hospital personnel and determination of their antibiotic sensitivity pattern. Iran South Med J 2014; 17(5): 916-26. [In Persian]

18. Ghasemian R, Najafi N, Shojai A. Nasal carriage and antibiotic resistance of Staphylococcus aureus isolates of razi hospital personel, Qaemshahr, 1382. J Mazandaran Univ Med Sci 2004; 14(44): 7987. [In Persian]

19. Askarian M, Zeinalzadeh A, Japoni A, Alborzi A, Memish ZA. Prevalence of nasal carriage of methicillin-resistant Staphylococcus aureus and its antibiotic susceptibility pattern in healthcare workers at Namazi hospital, Shiraz, Iran. Int J Infect Dis 2009; 13(5): e241-7. doi: 10.1016/j.ijid.2008. 11.026.

20. Rahimi-Alang S, Asmar M, Cheraghali F, Yazarlou S, Amini A, Shakeri F, et al. Frequency of methicillin resistant Staphylococcus aureus in health care. Zahedan J Res Med Sci 2011; 13(1): 17-22. [In Persian]

21. Rahbar M, Yaghoobi M, Kia-Darbandsari B. Prevalence of nasal carriage of Staphylococcus aureus and susceptibility of isolates to methicillin and mupirocin among healthcare workers in an Iranian hospital. Infect Control Hosp Epidemiol 2006; 27(3): 323-5.

22. Alavi SM, Rajabzadeh AR, Dezfoulian A, Haghighizadeh MH. Determination of nasal carriage of Staphylococcus aureus and antimicrobial resistance among hospital personnel in Razi hospital Ahwaz, spring
2003. Jundishapour Scientific Medical J 2006; 5(1): 378-84. [In Persian]

23. Zohorinia M, Soleymani E, Nobari H, Ahmadi K, Jafarian S, Bahmani N, et al. Frequency comparison of nasal and hand carriage of Staphylococcus aureus among the medical and non-medical staffs in Iranian air force Be'saat medical center. Annals of Military and Health Sciences Research 2006; 4(3): 901-7. [In Persian]

24. Khalili MB, Sharifi-Yazdi MK, Dargahi H, Sadeghian HA. Nasal colonization rate of Staphylococcus aureus strains among health care service employee's of teaching university hospitals in Yazd. Acta Medica Iranica 2009; 47(4): 315-7.

25. Nasiri B, Ghoutaslou R, Balali L, Darbijn A. Prevalence of nasal carriage of Staphylococcus aureus in Madani heart hospital, Tabriz. J Cardiovasc Thorac Res 2010; 2(3): 13-7.

26. Zeinalinia N, Pourmand MR, Qaneh M, Afrough P, Husseini M, Abdosamadi Z. Colonization rate of Staphylococcus aureus among health care service employee's of Tehran university hospitals. Hosp J 2011; 10(1): 71-6. [In Persian]

27. Jannati E, Arzanlou M, Habibzadeh S, Mohammadi S, Ahadi P, MohammadiGhalehbin B, et al. Nasal colonization of meca-positive, oxacillin-susceptible, methicillin-resistant Staphylococcus aureus isolates among nursing staff in an Iranian teaching hospital. Am J Infect Control 2013; 41(11): 1122-4. doi: 10.1016/j.ajic.2013.02. 012.

28. Mansourighiasi MA, Nasrollahiomran A, Hashemi M, Rajab Zadekanafi P, Jahangiri Rad Manjili M. The prevalence of antibiotic resistance pattern of Staphylococcus aureus isolated from nasal carriage of surgical 
ward's staff in Shahidrajaee hospital of Tonekabon, Iran. Med Lab J 2013; 7(1): 35-9. [In Persian]

29. Zadegan H, Menati S. The prevalence of methicillin and vancomycin resistant Staphylococcus aureus nasal carriage in large teaching hospital personnel. Afr J Microbiol Res 2011; 5(22): 3716-9. doi: 10.5897/ AJMR11.518.

30. Saadat S, Solhjoo K, Kazemi A, Mradaneh J. Antibiotic resistance pattern of Staphylococcus aureus strains isolated from personnel of Jahrom hospitals in 2012. Armaghane-danesh 2014; 18(10): 826-35. [In Persian]

31. Ohadian Moghadam S, Pourmand MR, Davoodabadi A. The detection of mupirocin resistance and nasal carriage of methicillin resistant Staphylococcus aureus among healthcare workers at university hospitals of Tehran, Iran. Iran J Public Health 2015; 44(3): 361-8.

32. Jomehpour N, Rezaei Manesh MR. Investigation of the frequency of Staphylococcus aureus carriers and its methicillin-resistant pattern in Torbat Heydariyeh hospitals staff in 2013. J Torbat
Heydariyeh Univ Med Sci 2016; 4(1): 42-9. [In Persian]

33. Kalhor H, Validi M, Nafisi MR. Frequency of Methicillin-resistant Staphylococcus isolated from nasal staff nurses in hospitals of Hajar Shahrecord. J Qom Univ Med Sci 2013; 7(1): 42-9. [In Persian]

34. Firouzi F, Akhtari J, Nasrolahei M. Prevalence of MRSA and VRSA strains of Staphylococcus aureus in healthcare staff and inpatients. J Mazandaran Univ Med Sci 2016; 26(142): 96-107. [In Persian]

35. Ohadian Moghadam S, Modoodi Yaghooti M, Pourramezan N, Pourmand MR. Molecular characterization and antimicrobial susceptibility of the CA-MRSA isolated from healthcare workers, Tehran, Iran. Microb Pathog 2017; 107: 409-12. doi: 10.1016/j. micpath.2017.04.027.

36. Madhumati B, Rajendran V, Ashwin K. Prevalence of mupirocin resistance in methicillin resistant Staphylococcus aureus strains isolated from a tertiary care hospital. Int J Curr Microbiol App Sci 2018; 7(5): 32936. doi: 10.20546/ijcmas.2018.705.042. 